\title{
STUDIES IN A-SCAN ECHOENCEPHALOGRAPHY. EVALUATION OF A PROPOSED TWO PHASE SHIFT
}

\author{
HeLio LeMmi \\ AMIN A. FARIS \\ JOSEPH BELLUOMINI
}

The use of ultrasound for diagnosis of intracranial pathology was introduced by Ballantine and associates ${ }^{1}$. Leksell 10,11 and Lithander ${ }^{12}$ further confirmed its value in clinical practice. These authors also contributed to the theoretical and practical applications of the A-scan Echoencephalograph. These reports were followed by those of Jeppson ${ }^{8}$, Ambrose ${ }^{1}$, and Ford and Ambrose 5, the latter report analyzing the findings in 1,000 cases and confirming the value of echoencephalography in demonstrating shifts of the midline intracranial structures in pathologic states. Similar conclusions were reached by Jefferson 6, Dreese and Netsky ${ }^{4}$, White and associates ${ }^{14}$, and Lapayowker and Christen ${ }^{9}$, and many others.

To date, $3 \mathrm{~mm}$ shift of the midline intracranial structures has been considered normal. In our experience much significant pathology is found in individuals demonstrating midline shifts within the border zones of $3 \mathrm{~mm}$. Establishment of an intermediary zone of midline shift around $3 \mathrm{~mm}$ between normal and abnormal seemed desirable and would be significant in alerting the physician to seek pathology by additional available means of diagnosis. The purpose of this study is to present data in support of this hypothesis.

We will not concern ourselves with the type and precise location of the neoplastic and other pathology encountered. Such discussions have been presented by several previous workers.

\section{MATERIAL AND METHODS}

Echoencephalography was performed on 440 consecutive cases. An Ekoline 20 Diagnostic Ultrasonoscope was used. This was equipped with a Polaroid LandCamera for permanent recording. The transducer probe was a barium titanate crystal with a diameter of $\mathbf{1 7 . 5} \mathrm{mm}$ operating at 2.25 megacycles with approximately 200 pulses per second and a pulse length of 1 microsecond. The recordings were performed by placing the transducer at the squamous portions of the temporal

From the Departments of Neurology and Pathology, Baptist Memorial Hospital and the University of Tennessee College of Medicine, Memphis, Tennessee. This study was partially supported by U.S.P.H. Grant NB-05274. 
bone $2 \mathrm{~cm}$ above the mandibular joint. The records were produced both the left and right side of the head and the two midline echos were compared. The final measurement was obtained from the average of several readings.

The patients were referred for this study with suspected intracranial pathology. The group was an adult one, the ages ranging from 17 to 74 years. The 440 cases were divided into three groups: Group $I$, normal midline measurement-that showed less than $2.5 \mathrm{~mm}$ shift (Table 1); Group II, borderline midline measurement-that showed 2.5 to $3.5 \mathrm{~mm}$ shift (Table 2); Group III, abnormal midline measurementdemonstrated more than $3.5 \mathrm{~mm}$ shift from midline (Table 3).

For convenience of analysis and comparison the three groups were divided into nine major categories of disease according to the final "signed out" diagnosis: 1) tumor; 2) sub-dural and epidural hematoma; 3) cerebral infarction; 4) intracerebral hematoma; 5) seizure; 6) headache; 7) contusion; 8) concussion; 9) miscellaneous. The miscellaneous group was further divided as shown in Table 4.

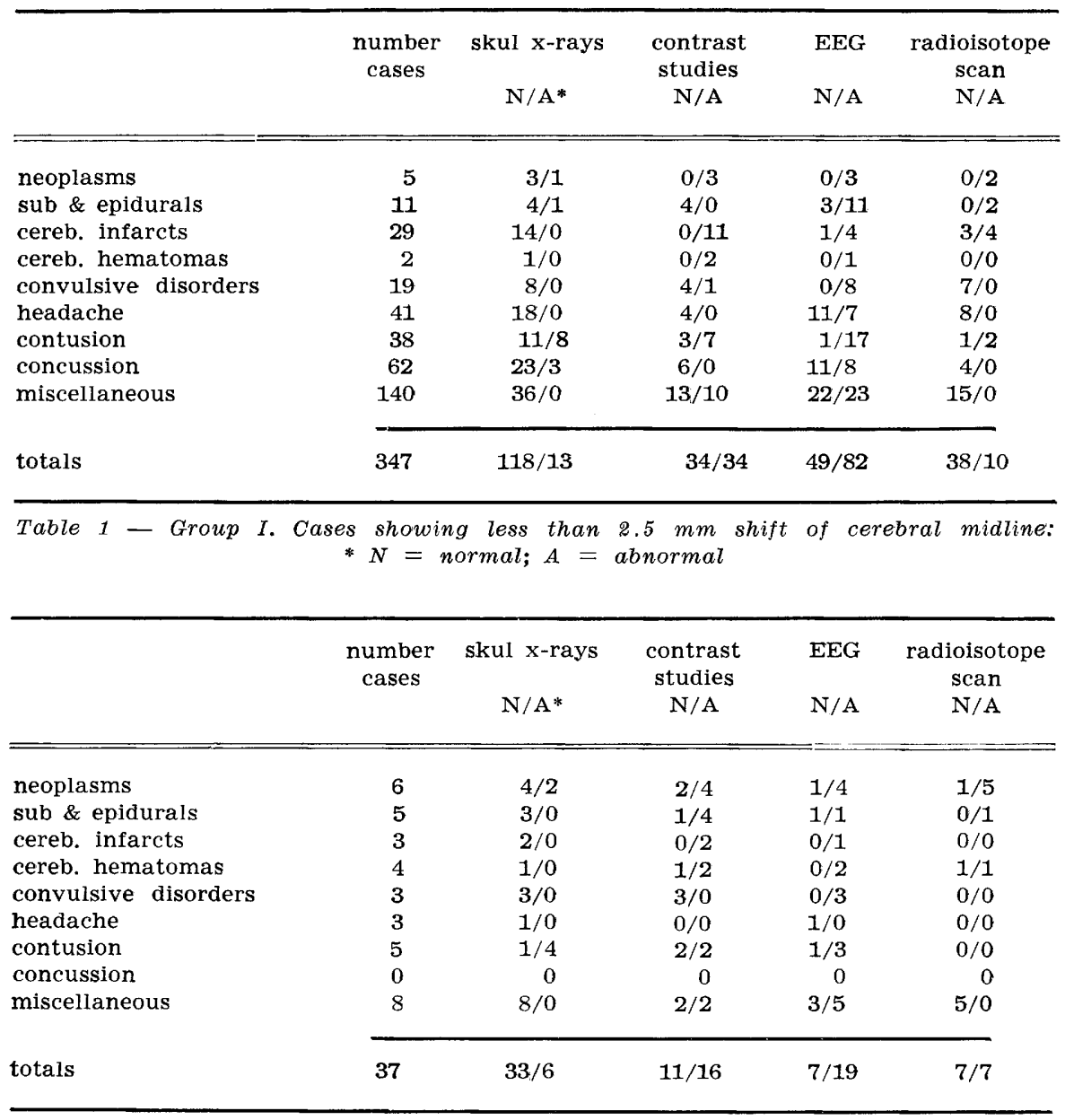

Table 2 - Group II. Cases showing $2.5-3.5 \mathrm{~mm}$ shift of cerebral midline. $\therefore N=$ normal; $A=$ abnormal 


\begin{tabular}{|c|c|c|c|c|c|}
\hline & $\begin{array}{c}\text { number } \\
\text { cases }\end{array}$ & $\begin{array}{c}\text { skul x-rays } \\
\text { N/A* }\end{array}$ & $\begin{array}{c}\text { contrast } \\
\text { studies } \\
\text { N/A }\end{array}$ & $\begin{array}{l}\text { EEG } \\
\text { N/A }\end{array}$ & $\begin{array}{c}\text { radioisotope } \\
\text { scan } \\
\text { N/A }\end{array}$ \\
\hline neoplasms & 27 & $13 / 6$ & $0 / 25$ & $0 / 27$ & $0 / 15$ \\
\hline sub \& epidurals & 23 & $9 / 5$ & $0 / 22$ & $0 / 13$ & $2 / 3$ \\
\hline cereb. infarcts & 1 & $1 / 0$ & $0 / 1$ & $0 / 1$ & $0 / 1$ \\
\hline cereb. hematomas & 3 & $0 / 0$ & $0 / 3$ & $0 / 3$ & $0 / 0$ \\
\hline convulsive disorders & 0 & 0 & 0 & 0 & 0 \\
\hline headache & 0 & 0 & 0 & 0 & 0 \\
\hline contusion & 1 & $0 / 1$ & $0 / 1$ & 0 & $0 / 0$ \\
\hline concussion & 0 & 0 & 0 & $0 / 1$ & 0 \\
\hline miscellaneous & 1 & $1 / 0$ & $0 / 1$ & $0 / 0$ & $0 / 0$ \\
\hline totals & 56 & $24 / 12$ & $0 / 53$ & $0 / 45$ & $2 / 19$ \\
\hline
\end{tabular}

Table 3 - Group III. Cases showing more than $3.5 \mathrm{~mm}$ shift of cerebral midline: * $N=$ normal; $A=$ abnormal

diagnosis

group I

group II

\begin{tabular}{|c|c|c|}
\hline transient ischemic attacks & 4 & 一 \\
\hline hypertension and syst. vasc. dis. & 10 & 一 \\
\hline Trauma without C.N.S. involv. & 17 & - \\
\hline psychiatric disorders & 20 & - \\
\hline $\begin{array}{l}\text { toxic and metabolic diseases } \\
\text { neurologic disorders: }\end{array}$ & 22 & 2 \\
\hline cereb. arteriosclerosis & 22 & 3 \\
\hline encephalitis & 11 & - \\
\hline subarach. hemorrhage & 8 & 3 \\
\hline vertigo & 8 & - \\
\hline basal ganglia dis. & 6 & - \\
\hline neuropathy & 5 & 一 \\
\hline hydrocephalus & 4 & - \\
\hline cortical atrophy & 3 & 一 \\
\hline totals & 140 & 8 \\
\hline
\end{tabular}

Table 4 - Breadown diagnosis of the miscellaneous category in Group I and Group II.

The diagnosis was most often verified by angiography, particularly in those patients suspected of having a space occupying lesion; pneumoencephalography was performed infrequently. Verification was also obtained by surgical exploration and/or autopsy. As indicated by the tabulations some patients were not subjected to any of these more elaborate diagnostic studies. A clinical follow-up of not less than six months was regarded as reliable evidence of absence of surgical and nonsurgical progressive lesions in these patients.

Concussion was accepted as the final diagnosis in those cases which suffered closed head injury with resultant brief period of unconsciousness and which had no clinical evidence of organic sequelae of central nervous system damage. Contusion was accepted as the diagnosis in those cases of closed head injury that, upon recovery from unconsciousness, had neurologic deficits of central origin. 
All the analyses were made without foreknowledge of the reason for which the study was performed. The results were tabulated and correlated with the clinical and other laboratory studies at a later date. The time interval between performance of the echoencephalogram and the contrast study, surgery and/or autopsy did not exceed in most instances a period of one week.

Mention of the pineal gland on plain skull x-rays will be omitted from the analysis; it was found to be visibly ealcified in less than $10 \%$ of these cases studied.

\section{RESULTS}

Group I totaled 347 cases interpreted as "normal" by echoencephalography because there was less than $2.5 \mathrm{~mm}$ shift of midline. The results of diagnostic studies of this group are shown in Table 1 . In this group there were 5 cases of intracranial neoplasm. One was a known astrocytoma of the right hemisphere that was re-operated without further contrast studies. One case was an astrocytoma of the cerebellum. Three additional cases showed shifts of the anterior cerebral artery exceeding $2 \mathrm{~mm}$ by arteriography: one a craniopharyngeoma, one a metastatic carcinoma and one a glioma. Cerebellar and midline cerebral tumors obviously are not expected to show a midline deviation. There were 7 subdural and 4 epidural hematomas. The epidural hematomas were diagnosed upon surgical exploration with no contrast studies having been performed. Four subdural hematomas were diagnosed by arteriography, but none showed any remarkable shift of midline structures. Of 29 cases of cerebral infarction, cerebral arteriography was done in 11 cases. Nine demonstrated more than $2 \mathrm{~mm}$ shift of the anterior cerebral artery; two demonstrated occlusive disease of the middle cerebral artery. The two cases of intracerebral hematoma diagnosed by arteriography showed shifts of the midline structures that were not demonstrated by echoencephalography. In the category of contusion, 10 of 38 cases were studied by cerebral angiography and seven showed bowing of the anterior cerebral arteries. Of these, four showed recognizable shift of the anterior cerebral arteries to one side or the other. In the miscellaneous group that has been tabulated separately in Table 4, eight cases of subarachnoid hemorrhage demonstrated the presence of berry aneurysms by arteriography but no shift of the midline structures.

In summary, in this group of 347 cases showing less than $2.5 \mathrm{~mm}$ shift, there were 33 cases that demonstrated significant intracranial pathology by other procedures, but that were missed by echoencephalography for a "miss rate" of roughly $10 \%$.

The results in Group II -37 cases - are summarized in Table 2. There were six cases of tumor. By arteriography four demonstrated definite shifts and two showed questionable shifts. There were five cases of subdural and epidural hematoma, four or which on contrast studies demonstrated midline shifts of over $2 \mathrm{~mm}$. There were also two cerebral hematomas, and two cases of contusion for a total of 17 cases $(46 \%)$ with significant intracranial pathology causing shift of the midline structures. The miscellaneous portion of the group is show in Table 4.

Group III - 56 cases summarized in Table 3 - demonstrated 27 tumors, 23 subdural or epidural hematomas, three intracerebral hematomas and one each of cerebral infarction, contusion and subarachnoid hemorrage due to berry aneurysm with dissection into the temporal lobe. Therefore, in these cases showing more than $3.5 \mathrm{~mm}$ shift there was $100 \%$ incidence of significant focal intracranial pathology. 


\section{DISCUSSION}

Previous workers studying the midline structures by echoencephalography have regarded a $3 \mathrm{~mm}$ shift as the upper limit of normal in adults. DeVlieger and Ridder ${ }^{3}$ studied 47 cases by this criterion, with confirmation of the midline by other studies in 45 . Jefferson ${ }^{7}$ in a series of 50 cases found $85 \%$ accuracy in the echoencephalographic as confirmed by other parameters. Lithander ${ }^{12}$ studied 373 patients, of which 229 were also examined by cerebral contrast studies. In this study, of the 83 patients with echoencephalographic displacement of the midline beyond $3 \mathrm{~mm}, 82$ were verified by radiography. Eight of 14 cases demonstrating lesser shifts were found to have significant shifts on a radiologic examination, but of 147 cases demonstrating midline echoencephalograms only eight were found to have significant midline shifts by intracranial contrast studies. Taylor et al. ${ }^{13}$ confirmed the midline measurement by contrast studies in $87 \%$ of 248 patients. Jeppson ${ }^{8}$ studied 579 cases, using the criteria of $3 \mathrm{~mm}$ shift as upper limit of normal, and divided his patients into groups of tumor, trauma and vascular disorders. In 12 cases the echoencephalogram was incorrect in the prediction of the midline position. Jefferson ${ }^{\top}$ concluded that echoencephalography was unreliable in $10 \%$ of 229 neurosurgical cases. In the study of Ford and Ambrose ${ }^{5}$ a series of 1,000 patients was reported of which 857 were subject to radiologic investigation. In this study the correlation rate was $95 \%$ in cases that had no significant intracranial pathology - showing no midline shifts - and $91 \%$ correlation with pathology in those cases showing displacement of midline structures.

In our experience there seemed to be unreliability of interpretation primarily in those echograms where the apparent shift fell within the range of $2.5-3.5 \mathrm{~mm}$. In order to test this impression, we elected to set arbitrarily the upper limits of normal deviation of the midline echo at $2.5 \mathrm{~mm} ; 2.5$ to 3.5 was designated as borderline; above $3.5 \mathrm{~mm}$ was to be regarded as abnormal. Use of these criteria afforded a practical and reliable basis for judgment within the results obtained in our study. Thus, of the 347 cases in Group I demonstrating less than $2.5 \mathrm{~mm}$ shift, the "miss" rate was an overall $10 \%$, correlating favorably with previous authors. In Group II, the overall rate of significant intracranial pathology was $46 \%$. In these cases the midline measurement fell almost equally on either side of the $3 \mathrm{~mm}$ point, indicating that a shift within this narrow range would have almost a $50 \%$ chance of demonstrating significant intracranial pathology.

Group III cases demonstrated $100 \%$ correlation with significant intracranial pathology, almost exclusively space occupying lesions as indicated in Table 3.

Table 5 shows the percentage incidence of the various pathologic states. It is interesting to note that with the increasing amount of shifts noted in the midline echoencphalography the space occupying lesions became more prominent. 
From the reported material in the literature and our present material it is clear that midline shifts of up to $2.5 \mathrm{~mm}$ seldom relate to intracranial pathology. Those cases demonstrating midline echo shift of 2.5 to $3.5 \mathrm{~mm}$ should have further clinical evaluation. A shift of $3.5 \mathrm{~mm}$ or more is very reliable evidence of a space occupying lesion.

Midline shift

\begin{tabular}{|c|c|c|}
\hline Normal & Borderline & Abnormal \\
\hline Midline Echo & Midline Echo & Midline Echo \\
\hline
\end{tabular}

\begin{tabular}{lrrrrrr}
\hline \hline neoplasms & 5 & $(1.4 \%)$ & 6 & $(16.2 \%)$ & 27 & $(48.0 \%)$ \\
sub \& epidurals & 11 & $(3.3 \%)$ & 5 & $(13.5 \%)$ & 23 & $(41.0 \%)$ \\
cereb. infarcts & 29 & $(8.4 \%)$ & 3 & $(8.1 \%)$ & 1 & $(1.8 \%)$ \\
cereb. hematomas & 2 & $(0.6 \%)$ & 4 & $(10.8 \%)$ & 3 & $(5.4 \%)$ \\
convulsive disorders & 19 & $(5.5 \%)$ & 3 & $(8.1 \%)$ & 0 & $(1.8 \%)$ \\
headache & 41 & $(11.8 \%)$ & 3 & $(8.1 \%)$ & 0 & \\
contusion & 38 & $(11.0 \%)$ & 5 & $(13.5 \%)$ & 1 & $(1.8 \%)$ \\
concussion & 62 & $(18.0 \%)$ & 0 & & 0 & \\
miscellaneous & 140 & $(40.0 \%)$ & 8 & $(21.6 \%)$ & 1 & $(100.0 \%)$ \\
totals & 347 & $(100.0 \%)$ & 37 & $(100.0 \%)$ & 56 & $(10)$
\end{tabular}

Table 5 - Comparative incidence of the different categories of diagnosis in the groups of patients.

\section{S U M M A R Y}

A series of 440 patients studied by echoencephalography is reported. Rather than dividing the patients in the classic two groups of less than $3 \mathrm{~mm}$ and more than $3 \mathrm{~mm}$ deviation of the midline, the patients in this study were divided into three groups, correlating the degree of midline shift to the presence of intracranial pathology. Group I, showing 0 to $2.5 \mathrm{~mm}$ shift proves to be normal with a "miss" rate of only $10 \%$. Group II, showing 2.5 to $3.5 \mathrm{~mm}$ shift is regarded as a borderline group with an incidence of significant intracranial pathology of $46 \%$, clearly indicating the need for further evaluation. Group III, demonstrating greater than $3.5 \mathrm{~mm}$ shift from the midline, is designated with confidence as abnormal, with a yield of significant intracranial pathology of $100 \%$ in this study.

\section{R E S U M O}

Os autores estudaram por meio do ecoencefalógrafo 440 pacientes os quais foram divididos em três grupos, de acôrdo com a medida do desvio das estruturas centrois do cérebro (ao contrário dos clássicos dois grupos - 
com menos de $3 \mathrm{~mm}$ e mais de $3 \mathrm{~mm}$ de desvio). Subseqüentemente cada um dos três grupos foi analisado com relação ao diagnóstico final de cada paciente. Os pacientes do grupo I, com desvio máximo de 2,5 $\mathrm{mm}$ e considerados normais com relação ao ecoencefalograma, apresentaram aproximadamente $10 \%$ de patologia intracraniana que não foi denunciada pelo eco. O grupo II, considerado questionável e com desvio de 2,5 até $3,5 \mathrm{~mm}$, mostrou uma incidência de patologia intracraniana de $46 \%$ e, porisso mesmo, claramente necessita outros meios diagnósticos. No grupo III, com mais de $3,5 \mathrm{~mm}$ de desvio e considerado anormal, quase todos os doentes apresentaram patologia intracraniana séria, principalmente de ordem tumoral.

\section{REFER E N C E S}

1. AMBROSE, J. - Pulsed ultrasound: illustrations of clinical applications. Brit. J. Radiol. 37:165, 1964.

2. Ballantine, H. T.; BOLT, R. H.; HUETER, T. F. \& LUDWIG, G. D. - On detection of intracranial pathology by ultrasound. Science 112:525, 1950.

3. DeVLIEGER, M. \& RIDDER, H. J. - Use of echoencephalography. Neurology (Minneapolis) 9:216, 1959.

4. DREESE, M. J. \& NETSKY, M. G. - The clinical use of echoencephalography. Virg. Med. month 90:539, 1963.

5. FORD, R. \& AMBROSE, J. - Echoencephalography: the measurement of the position of mid-line structures in the skull with high frequency puised ultrasound. Brain 86:189, 1964.

6. JEFERSON, A. - Some experiences with echoencephalography. J. Neurol. Neurosurg. a. Psychiat. 22:83, 1959.

7. JEFFERSON, A. - Clinical experiences with echoencephalography. Acta neurochir. 10:392, 1962.

8. JEPPSON, S. - Echoencephalography: the midline echo. An evaluation of its usefulness for diagnosing intracranial expansivities and an investigation into its sources. Acta. chir. Scand. Suppl. 272, 1961.

9. LAPAYOWKER, M. S. \& CHRISTEN, G. E. - Echoencephalography in general hospital practice. Amer. J. Roentgen. Radiother. a. nuc. Med. 93:803, 1965.

10. LEKSELL, L. - Echo-encephalography: detection of intracranial complications following head injury. Acta. chir. Scand. 110:301, 1955-1956.

11. LEKSELL, L. - Echo-encephalography: midline echo from the pineal body as an index of pineal displacement. Acta. chir. Scand. 115:255, 1958.

12. LITHANDER, B. - Clinical and experimental studies in echoencephalography. Acta. psychiat. Scand., Suppl. 159, 1961. 
206 ARQ. NEURO-PSIQUIAT. (SÄO PAULO) VOL. 27, N.० 3, SETEMBRO, 1969

13. TAYLOR, J. C.; NEWELL, J. A. \& KARVOUNIS, P. - Ultrassonics in the diagnosis of intracranial space occupying lesions. Lancet 1:1197-1199, 1961.

14. WHITE, D. N.; CheSEbROUGH, J. M. \& BLANCHARD, J. B. - Studies in ultrasonic echoencephalography: A-Scan determination of the M-echo position in a group of patients. Neurology (Minneapolis) 15:81, 1965.

62 South Dunlap - Memphis, Tennessee 38103 - U.S.A. (Dr. H. Lemmi address). 